\title{
Endotracheal tube malposition within the pediatric population: a common event despite clinical evidence of correct placement
}

\author{
[Mauvais positionnement du tube endotrachéal dans une population pédiatrique: \\ un événement courant malgré des données cliniques suggérant un positionnement
} correct]

Eric A. Harris MD MBA, ${ }^{*}$ Kristopher L. Arheart EdD, $\uparrow$ Donald H. Penning MD*

Purpose: To ensure that the endotracheal tube (ETT) is ideally placed for proper ventilation, radiographic confirmation of ETT placement is frequently used to supplement clinical examination in the intensive care unit setting. However, fluoroscopy rarely serves the same role during surgery, despite the fact that portable units are often present in the operating room. The purpose of this study was to ascertain the value of fluoroscopy in determining ETT malposition among the pediatric surgical population.

Methods: Chest radiographs from 257 children (age 12 days$12 \mathrm{yr}$ ), who presented for a total of 446 individual procedures in the fluoroscopy suite, were studied to determine the incidence of ETTs placed too shallow (above the inferior clavicular border) or too deep (at or below the carina). A logistic regression with outcomes of correct and incorrect was used to analyze the data points.

Results: Eighteen percent of all the radiographs showed initial improper ETT placement, despite clinical evidence suggesting the contrary. The peak incidence of malposition, which occurred in patients under one year old, reached $35 \%$. Incidence decreased with advancing age, but remained over $10 \%$ until the age of ten. A second attempt at positioning the tube, based on information from the chest radiograph, was successful in $95 \%$ of the cases. The remaining $5 \%$ required placement of the ETT under continuous fluoroscopic guidance.

Conclusion: Fluoroscopy, when readily available in the operating room, is a safe and useful technique to ensure proper ETT placement among the pediatric population.
CAN J ANESTH 2008/55: 10 / pp 685-690

Objectif : Lorsqu'on veut s'assurer que le tube endotrachéal est adéquatement placée pour une bonne ventilation, la confirmation radiographique du positionnement du tube est souvent utilisée pour complémenter l'examen clinique dans l'unité des soins intensifs. Cependant, il est rare que la fluoroscopie joue le même rôle pendant la chirurgie, malgré le fait que des unités portables soient souvent à disposition dans la salle d'opération. L'objectif de cette étude était de confirmer la valeur de la fluoroscopie pour détecter le mauvais positionnement du tube endotrachéal chez des patients de chirurgie pédiatriques.

Méthode : Les radiographies du thorax de 257 enfants (âgés de 12 jours à 12 ans) qui ont subi un total de 446 interventions individuelles dans la salle de fluoroscopie, ont été étudiées afin de déterminer l'incidence de tubes endotrachéaux positionnées au dessus de la ligne claviculaire (pas assez profond) ou à ou au dessous de la carène (trop profond). Une analyse par régression logistique avec le binôme correct / incorrect a été utilisée pour évaluer les points de données.

Résultats : Au total, $18 \%$ des radiographie ont montré un positionnement initialement inadéquat du tube endotrachéal, malgré le fait que les données cliniques suggéraient le contraire. L'incidence maximale de mauvais positionnement, qui a été observée chez les patients de moins d'un an, a atteint $35 \%$. L'incidence diminuait

From the Departments of Anesthesiology, Perioperative Medicine, and Pain Management, ${ }^{*}$ and Epidemiology and Public Health, $\dagger$ University of Miami / Miller School of Medicine, Miami, Florida, USA.

Address correspondence to: Dr. Eric A. Harris, 2574 Mayfair Ln., Weston, FL 33327-1506, USA. Phone: 305-585-5094; Fax: 305-585-

8127; E-mail: eharris2@med.miami.edu

Source of financial support: Departments of Anesthesiology, Perioperative Medicine, and Pain Management, University of Miami /

Miller School of Medicine, Miami, Florida, USA.

Accepted for publication June 20, 2008.

Revision accepted July 15, 2008.

Final revision accepted July 21, 2008. 


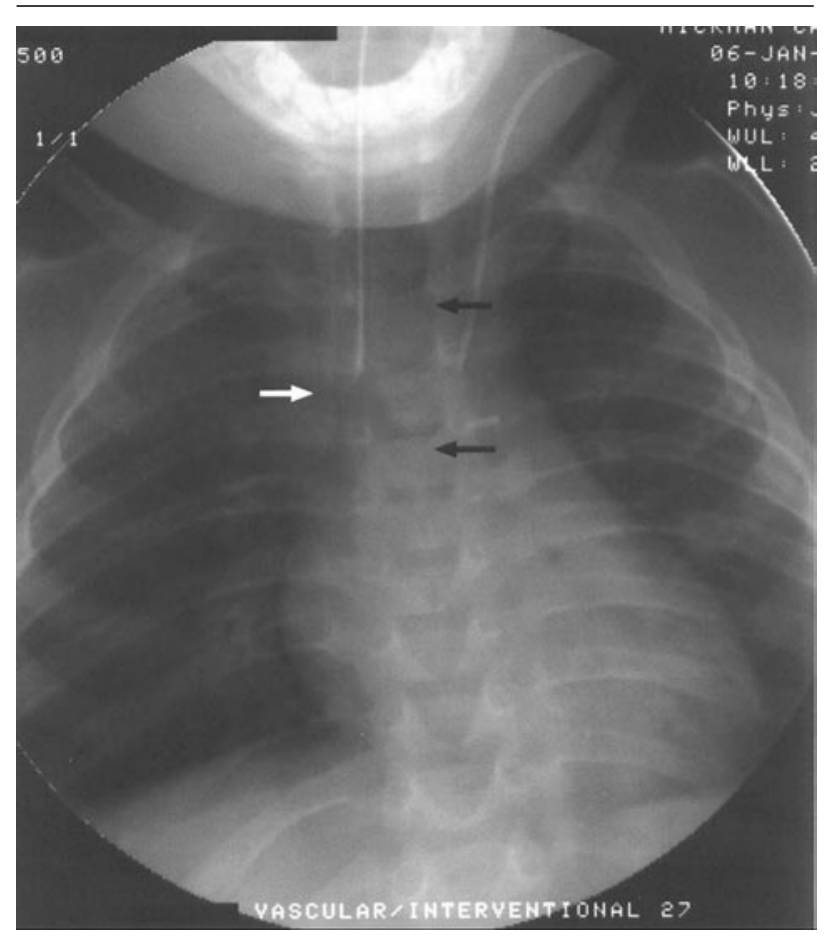

FIGURE 1 A properly placed endotracheal tube (ETT). In all radiographs, the upper black arrow points to the inferior clavicular line, the lower black arrow points to the carina, and the white arrow points to the tip of the ETT.

avec l'âge, mais demeurait au dessus de 10 \% jusqu'à dix ans. Une deuxième tentative de positionnement de la sonde sur la base des informations tirées de la radiographie du thorax, a été réussie dans $95 \%$ des cas. Les $5 \%$ restants ont nécessité un positionnement de la sonde endotrachéale sous monitorage fluoroscopique continu.

Conclusion: Lorsqu'elle est à portée de main dans la salle d'opération, la fluoroscopie est une technique sécuritaire et utile pour s'assurer du positionnement correct du tube endotrachéal dans une population pédiatrique.

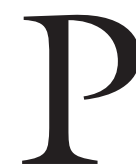

LACING the endotracheal tube (ETT) into the trachea is only part of the challenge in ensuring correct endotracheal tube positioning in a pediatric patient. Achieving the proper depth of ETT insertion is also critical, although an ETT improperly positioned within the trachea is often more difficult to ascertain than an esophageal intubation. The clinician often must rely upon inexact signs, such as the presence of auscultated breath sounds in all lung fields, bilateral chest rise, and ultimately the continuous presence of a normal end-tidal $\mathrm{CO}_{2}$ $\left(\mathrm{ETCO}_{2}\right)$ curve. While such signs ensure that the tube is positioned within the trachea, they do not guarantee

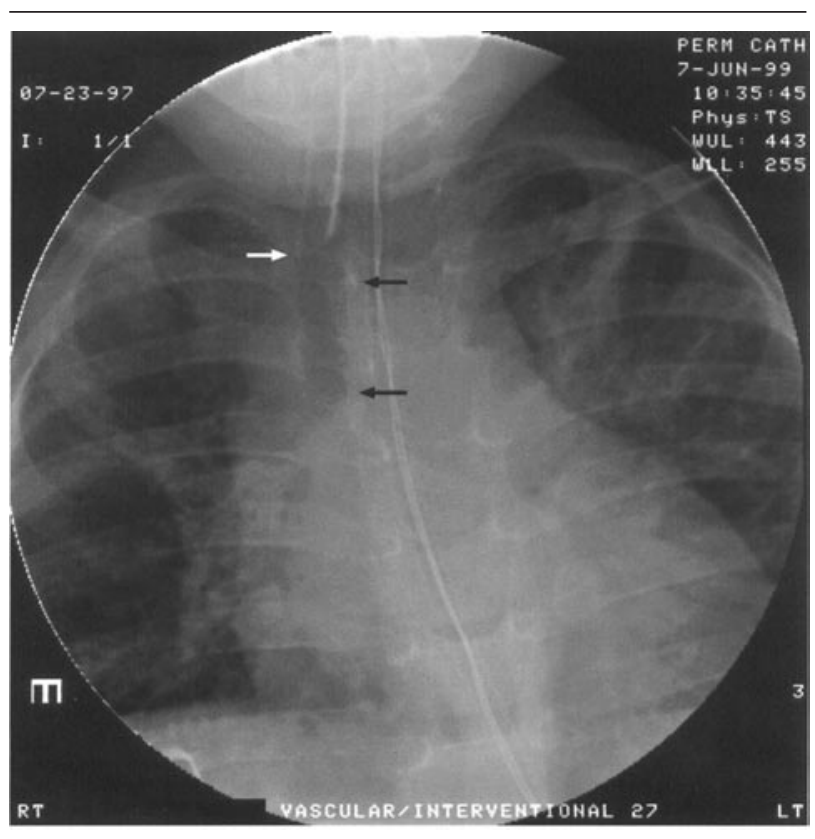

FIGURE 2 The endotracheal tube is placed proximal to the inferior clavicular line.

ideal ETT positioning between the inferior clavicular border and the carina (Figure 1). Paradoxically, such signs may be present even when the ETT is too shallow (tip above the inferior clavicular border, Figure 2) or too deep (tip at or below the carina, Figure 3). This is a particular problem in the pediatric patient population because the margin for error is so small. Evidence indicates that factors such as uncuffed tubes and the presence of the Murphy eye may suggest proper tube placement when the tip of the tube is, in fact, in an endobronchial location. ${ }^{1}$ In the setting of emergent intubation ${ }^{2}$ or in the intensive care unit (ICU), ${ }^{3-5}$ where prolonged intubation is anticipated, chest radiographs are widely used to ascertain ETT location. However, they are rarely used in the operating room for this same purpose. In this study, the authors examined chest radiographs from 257 pediatric patients over a seven-year period to verify proper depth of ETT insertion. We hypothesized that malposition of ETTs in pediatric patients would be fairly common, despite clinical confirmation of adequate positioning. A secondary outcome of interest was to validate our theory that the incidence of malposition would decrease inversely with age.

\section{Methods}

The protocol for this study was submitted to our Institutional Review Board as a retrospective review 


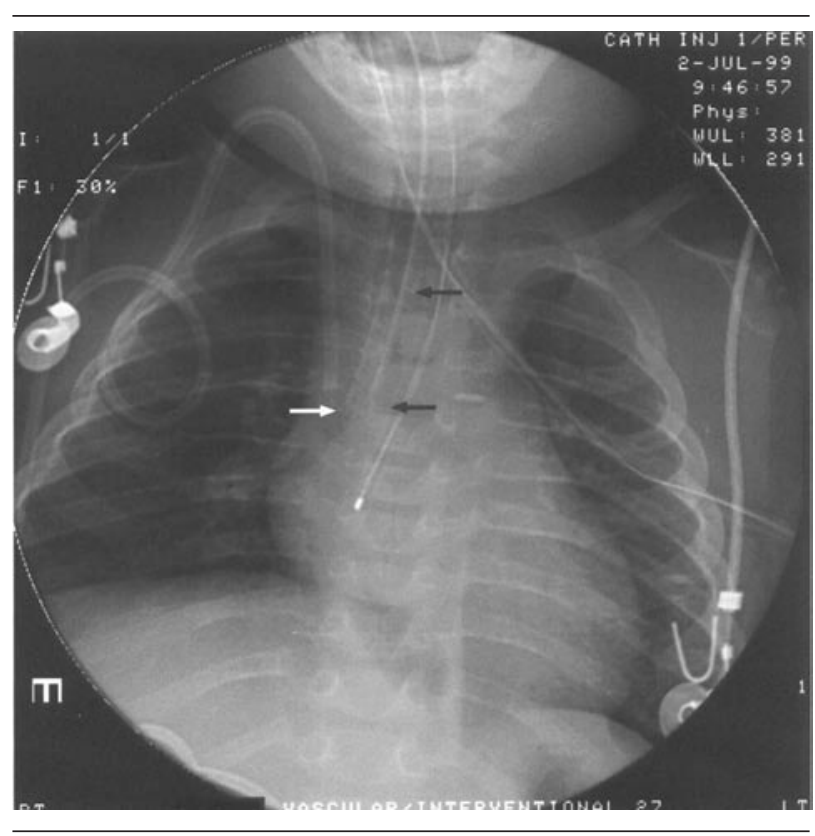

FIGURE 3 The endotracheal tube is resting against the carina.

of anesthetic records and chest radiographs. The data were examined in three broad age brackets with patient identifiers removed. At the time of the medical procedures, there was no plan to examine the data or to incorporate it into a study; informed consent was therefore waived by the Institutional Review Board.

Using a computer database belonging to the Department of Radiology, we identified all pediatric patients (age 12 days-12 yr old) who underwent interventional radiologic vascular access or biliary procedures from January 1, 1999 to December 31, 2006. These patients' anesthetic charts (manual or electronic) were then reviewed to exclude patients who did not receive general endotracheal anesthesia. Patients were also excluded from the study if they displayed any anatomic alteration of upper airway anatomy, if they had an active tracheostomy, if their tracheae were intubated with the assistance of a fibreoptic bronchoscope, or if they were already intubated on arrival to the radiology suite. We identified two hundred fifty-seven eligible patients who underwent a total of 446 discrete procedures on different occasions (Table I). The sample size was determined solely by the number of children presenting for care during the time interval we examined; no a priori sample size was calculated. All patients underwent either an intravenous or an inhalational induction and were orally intubated with a Mallinckrodt ETT (Mallinckrodt Tyco Healthcare, Hazelwood, MO, USA). The size of the tube, as well as the presence or
TABLE I Age distribution and observed and predicted probabilities of misplaced endotracheal tube

\begin{tabular}{llll}
\hline Age $(y r)$ & \# of Cases & Observed & $\begin{array}{l}\text { Predicted } \\
\text { (95\% confidence interval) }\end{array}$ \\
\hline$<1$ & 69 & 0.377 & $0.364(0.281-0.456)$ \\
$1-<2$ & 112 & 0.214 & $0.212(0.163-0.270)$ \\
$2-<3$ & 39 & 0.128 & $0.147(0.102-0.206)$ \\
$3-<4$ & 43 & 0.093 & $0.116(0.076-0.174)$ \\
$4-<5$ & 38 & 0.211 & $0.120(0.079-0.179)$ \\
$5-<6$ & 49 & 0.122 & $0.128(0.081-0.198)$ \\
$6-<7$ & 10 & 0.100 & $0.140(0.083-0.227)$ \\
$7-<8$ & 17 & 0.176 & $0.148(0.082-0.251)$ \\
$8-<9$ & 17 & 0.059 & $0.142(0.075-0.251)$ \\
$9-<10$ & 13 & 0.154 & $0.116(0.055-0.229)$ \\
$10-<11$ & 11 & 0.000 & $0.075(0.024-0.209)$ \\
$11-<12$ & 14 & 0.143 & $0.035(0.005-0.199)$ \\
$12-<13$ & 14 & 0.000 & $0.011(0.001-0.194)$ \\
\hline
\end{tabular}

absence of a cuff, were at the discretion of the attending anesthesiologist. All children three years or younger were managed with uncuffed tubes, while all children eight years or older received cuffed tubes. Among the children age four to seven years, 65/114 (57\%) underwent endotracheal intubation with uncuffed tubes. As per institutional protocol, tube position was confirmed and documented by the presence of bilateral breath sounds, the absence of epigastric breath sounds, the observation of bilateral chest rise, and the continued (> 6 breaths) presence of $\mathrm{ETCO}_{2}$. All signs were checked by a CA-2 or CA-3 resident or a CRNA, and they were confirmed by the attending anesthesiologist. As per the attending's discretion, additional methods, (e.g., intentional endobronchial intubation followed by withdrawal of the tube, direct visualization of tube markings at the vocal cords, or the use of a mathematical formula to ascertain depth) were used to ensure proper ETT placement. However, these methods were not universally practiced and documented on the anesthesia records, and therefore were not included as standard confirmation techniques in this study. After the tube was secured with tape at the mouth, the radiologist performing the assessment directed the proper positioning of the patient for the procedure (e.g., head rotation and extension). After final positioning, the patient's body was secured with Velcro straps, and the ETT position was rechecked using the criteria described above. If, at this point, the physical examination suggested that the tube had shifted during patient positioning, the tube was repositioned, rechecked, and re-secured prior to starting the procedure.

Upon initiation of the surgical procedure, the anesthesiologist viewed the fluoroscopy monitor to ascertain the position of the ETT via a postero-anterior (PA) radiograph. If the ETT's position was noted to 
be either too deep (at or below the carina), or too shallow (above the clavicles), the radiologist was asked to pause the procedure while the tube was repositioned based on evidence from the fluoroscopic image. After securing the tube, fluoroscopy was resumed, and the tube position was rechecked on the monitor once again. If the ETT was found to be misplaced for a second time, it was subsequently adjusted and secured under continuous fluoroscopic guidance.

\section{Statistical considerations}

The median age at the time of the procedure was three years, with a range in age from 19 days to 12 yr. We investigated the effect of age on misplacement of the ETT by means of logistic regression. Age was considered as a continuous variable in all models, and we included quadratic and cubic terms to allow for nonlinearity in the effect. First, we fit an ordinal logistic regression model with ordered outcomes (too deep, correct, too shallow), but the assumption of proportional odds was untenable. ${ }^{7}$ Next, we fit a multinomial logistic regression model with "correct" as the reference group. However, there were very few events in the "too shallow" group, and, since the estimated coefficients for the effect of age were similar for "too shallow" and "too deep", we proceeded to fit a single binary logistic regression model. Finally, since more than half $(54 \%)$ of the children in this study were measured more than once, we used generalized estimating equations ${ }^{7}$ to account for any correlation between measurements on the same patient. This final model is reported here in Table II.

We divided the ages into one-year age bins and calculated the probability of a misplaced ETT as the frequency of incorrectly placed ETT divided by the number of observations on the age bin. The predicted probability and the $95 \%$ confidence interval were calculated from the logistic regression equation. First, we obtained the $\log$ odds by evaluating the logistic regression equation for a particular age, and then we calculated the $95 \%$ confidence intervals of the log odds. By exponentiating the $\log$ odds and the $95 \%$ confidence intervals, we obtained the odds and the 95\% confidence intervals. A simple algebraic manipulation of the odds and the $95 \%$ confidence intervals $[$ probability $=$ odds $/(1+$ odds $)]$ yields the probability and the $95 \%$ confidence interval. ${ }^{7}$ The observed and predicted probabilities for the one-year age bins are given in Table I. A graph of the observed probabilities for the one-year age bins and the predicted probabilities with $95 \%$ confidence bands for continuous age is presented in Figure 4. The interpretation of the model shown in Figure 4 is that as age increases, the probability of an incorrect placement decreases.

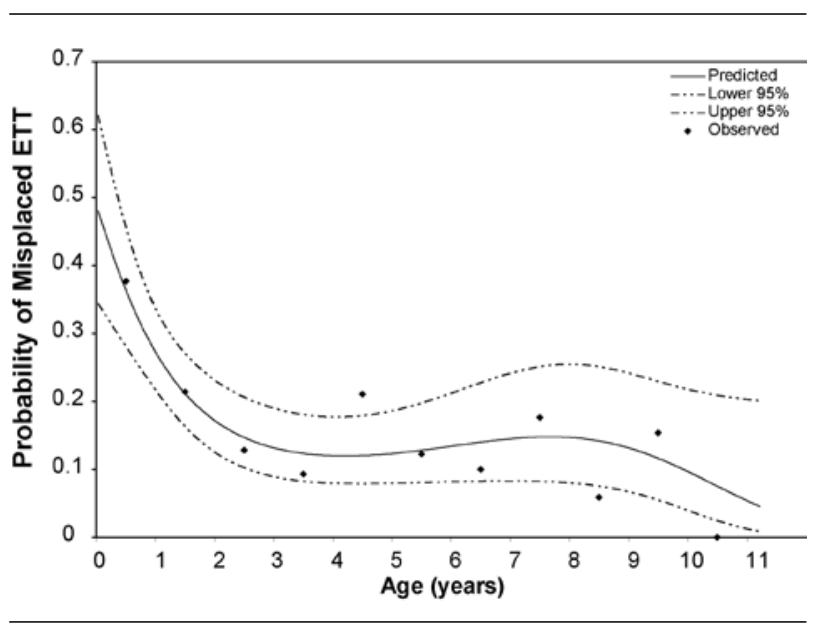

FIGURE 4 Observed and predicted probability (with 95\% confidence intervals) of incorrect endotracheal tube (ETT) placement. Observed points are the probabilities of an incorrect ETT placement at the centre of one-year age bins. Predicted probability and $95 \%$ confidence intervals are calculated from a cubic polynomial logistic regression of incorrect ETT placement on age as a continuous variable.

TABLE II Results on age of a cubic polynomial logistic regression of incorrect endotracheal tube placement

\begin{tabular}{lll}
\hline Parameter & Estimate \pm standard error & P-value \\
\hline Intercept & $-0.04 \pm 0.30$ & 0.890 \\
Age & $-1.14 \pm 0.31$ & $<0.001$ \\
Age $^{2}$ & $0.21 \pm 0.08$ & 0.005 \\
Age $^{3}$ & $-0.01 \pm 0.01$ & 0.014 \\
\hline
\end{tabular}

\section{Results}

Chest radiographs of 446 procedures were reviewed for correct ETT placement. Correct placement was found in $364(82 \%)$ of cases, while $60(13 \%)$ were too deep and $22(5 \%)$ were too shallow. Among the 60 cases where the ETT was too deep, 47 films $(78.3 \%)$ showed the ETT abutting the carina, 11 (18.3\%) displayed a right endobronchial intubation (Figure 5), and two (3.3\%) showed a left endobronchial intubation (Figure $6)$. On the second attempt, the ETT was correctly replaced in $95 \%$ of the 82 total cases of misplacement; by the third try, the remaining $5 \%$ were correctly placed under continuous fluoroscopic guidance.

\section{Discussion}

We may easily overestimate our success rate in the skill of proper placement of ETTs within the pediatric population. According to the ASA Closed Claims Project, the combination of inadvertent extubation (ETT positioned proximally in the pharynx) and mainstem intubation accounted for $4 \%$ of adverse respiratory events among the pediatric population. ${ }^{7}$ 


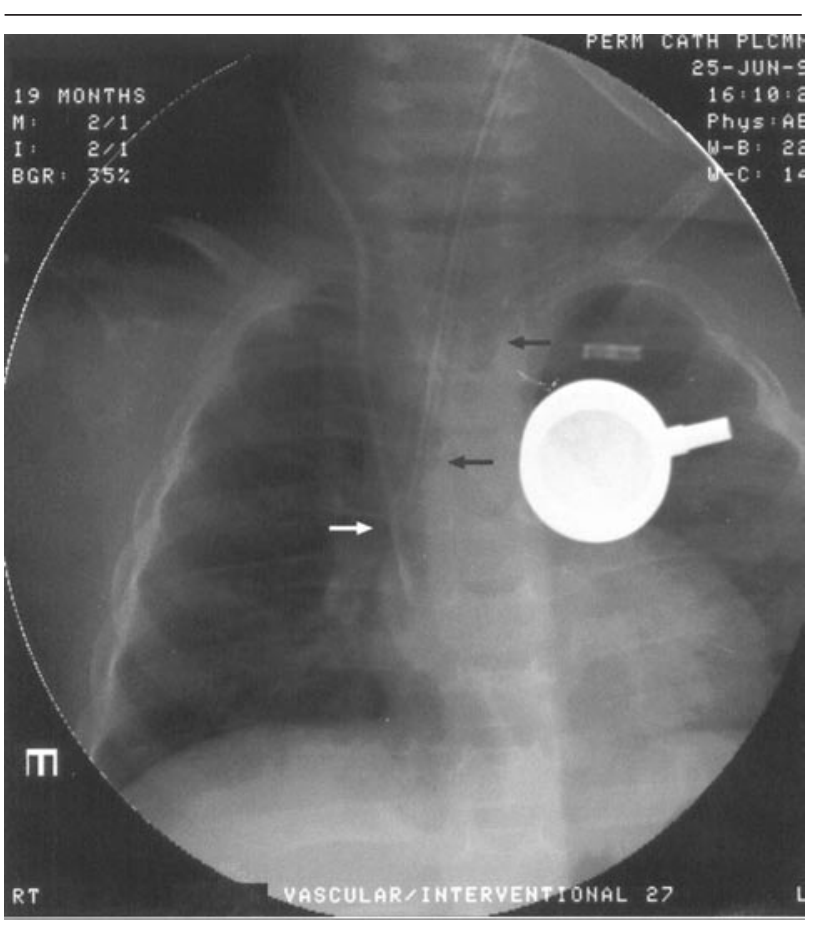

FIGURE 5 A right endobronchial intubation.

While many methods have been suggested to ascertain ETT placement, the PA chest radiograph presents incontrovertible evidence as to the location of the tip of the tube. While chest films are frequently used to check ETT position in the ICU setting, ${ }^{3-5}$ they have not been routinely used in operating rooms. Instead, clinicians often rely upon notoriously unreliable signs, such as bilateral breath sounds and chest excursion. ${ }^{1,8}$ Other clinicians suggest continuous monitoring of pulmonary compliance ${ }^{9}$ or peak inflation pressures, ${ }^{10}$ transillumination using the Trachlight ${ }^{\mathrm{TM}},{ }^{11}$ computerized analysis of electronic auscultation, ${ }^{12}$ or suprasternal palpation. ${ }^{13}$ Mathematical formulae to estimate proper insertion depth [triple the internal diameter of the ETT, ${ }^{14,15} 6$ plus the neonates weight in kilograms ${ }^{16}$ (the 7-8-9 rule)] have recently fallen into disfavour due to their poor success rates.

Due to the two-dimensional nature of the film, anterioposterior chest radiographs may incorrectly suggest that an ETT in the esophagus is actually in the trachea. ${ }^{17,18}$ However, clinical monitoring of $\mathrm{ETCO}_{2}$ and pulse oximetry is a sensitive method to distinguish between an esophageal and a tracheal intubation. Once an esophageal intubation has been ruled out, the PA chest radiograph remains the gold standard to assess insertion depth. Repositioning the patient's head after the ETT has been secured can significantly alter the position of the distal tip of the tube. ${ }^{19,20}$ To

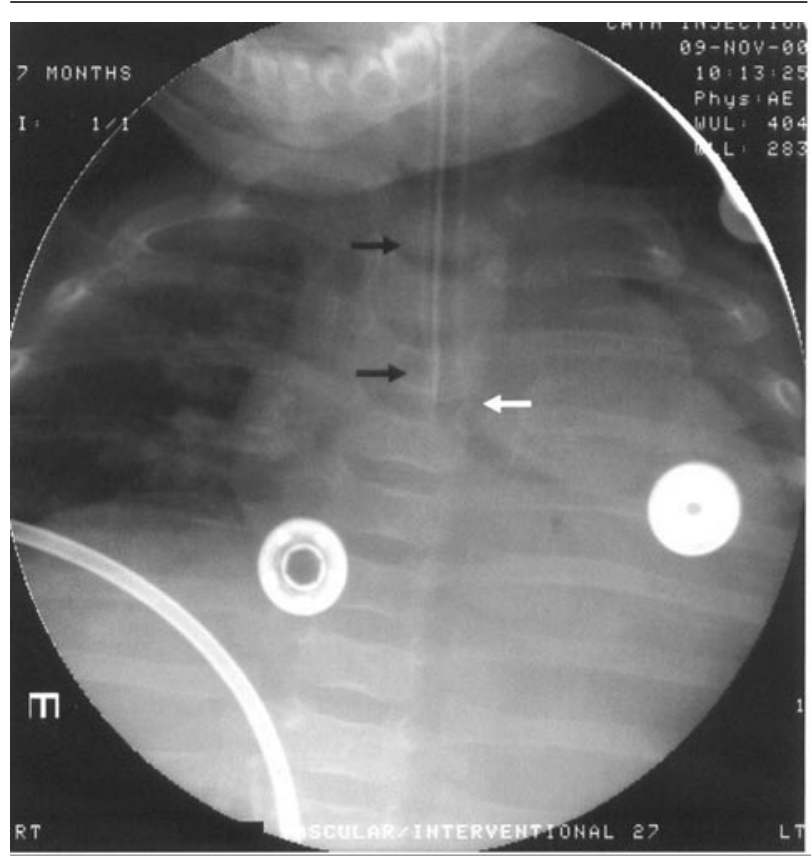

FIGURE 6 A relatively rare left endobronchial intubation.

avoid unnecessary radiation exposure and a false sense of security, the chest radiograph should be performed after the patient has been properly positioned for the surgical procedure.

Anecdotal reports exist concerning the use of fluoroscopy to ensure proper ETT placement, ${ }^{21,22}$ yet few clinicians seem to regularly use chest radiographs to ascertain ETT positioning in the operating room. Our study shows that ETTs malpositioned within the trachea are a common occurrence, reaching a peak of over $35 \%$ in children less than 12 months of age. The incidence drops sharply as age increases, but remains over $10 \%$ until the age of ten.

One limitation of our study is that it reflects only one institution's practice guidelines. The majority of our intubations in this study were performed by residents and CRNAs, with the attending anesthesiologist intubating only after two unsuccessful attempts. Due to the number of these cases, we did not look for a difference in the success rate with respect to the experience of the intubator. A hospital where the procedures are performed by pediatric anesthesiologists may obtain very different results; however, a large number of routine pediatric cases are completed each year by anesthesiologists without such fellowship training.

While it is impractical to suggest that fluoroscopic confirmation of ETT depth should be the standard of care in all pediatric cases, C-arm fluoroscopy is already 
being used during many pediatric surgical procedures (spine surgery, orthopedic surgery, etc.). Since the hardware is already available in the operating room, the time needed to obtain a chest film is negligible, and the patient's additional exposure to radiation $(6 \mathrm{mrem})^{\mathrm{A}}$ is inconsequential considering the patient's total exposure during the procedure may be thousands of times greater. The relatively high incidence of inadvertently misplaced ETTs discovered in this study suggests that fluoroscopy, when readily available, is a safe and useful technique to ensure proper ETT placement among the pediatric population. This technique has become the standard of care in our institution for all children 12 and under who are intubated for a procedure in any of the radiology suites. A prospective clinical study should confirm our results. It might also prove useful to assess the value of fluoroscopy when other methods of ETT confirmation are universally used (e.g., intentional mainstem intubation followed by withdrawal of the tube until bilateral breath sounds are heard).

\section{References}

1 Verghese ST, Hannallah RS, Slack MC, Cross RR, Patel $K M$. Auscultation of bilateral breath sounds does not rule out endobronchial intubation in children. Anesth Analg 2004; 99: 56-8.

2 Loew A, Thibeault DW. A new and safe method to control the depth of endotracheal intubation in neonates. Pediatrics 1974; 54: 506-8.

3 Owen RL, Cheney FW. Endobronchial intubation: a preventable complication. Anesthesiology 1987; 67: 255-7.

4 Brunel W, Coleman DL, Schwartz DE, Peper E, Cohen $N H$. Assessment of routine chest roentgenograms and the physical examination to confirm endotracheal tube position. Chest 1989; 96: 1043-5.

5 Lotano R, Gerber D, Aseron C, Santarelli R, Pratter $M$. Utility of postintubation chest radiographs in the intensive care unit. Crit Care 2000; 4: 50-3.

6 Caplan RA, Posner KL, Ward RJ, Cheney FW. Adverse respiratory events in anesthesia: a closed claim analysis. Anesthesiology 1990; 72: 828-33.

7 Hosmer DW, Lemeshow S. Applied Logistic Regression, $2^{\text {nd }}$ ed. New York: John Wiley \& Sons; 2000.

8 Sugiyama K, Yokoyama K, Satoh K, Nishihara $M$, Yoshitomi T. Does the Murphy eye reduce the reliability of chest auscultation in detecting endobronchial intubation? Anesth Analg 1999; 88: 1380-3.

9 Visaria RK, Westenskow DR. Model-based detection of endobronchial intubation. Anesth Analg 2006; 103: 888-93.

10 Campos C, Naguib SS, Chuang AZ, Lemak NA, Khalil $S N$. Endobronchial intubation causes an immediate increase in peak inflation pressure in pediatric patients. Anesth Analg 1999; 88: 268-70.

11 Locker GJ, Staudinger T, Knapp S, et al. Assessment of the proper depth of endotracheal tube placement with the Trachlight. J Clin Anesth 1998; 10: 389-93.

12 O'Connor CJ, Mansy H, Balk RA, Tuman KJ, Sandler $R H$. Identification of endotracheal tube malpositions using computerized analysis of breath sounds via electronic stethoscopes. Anesth Analg 2005; 101 : 735-9.

13 Bednarek FJ, Kuhns LR. Endotracheal tube placement in infants determined by suprasternal palpation: a new technique. Pediatrics 1975; 56: 224-9.

14 Phipps LM, Thomas NJ, Gilmore RK, et al. Prospective assessment of guidelines for determining appropriate depth of endotracheal tube placement in children. Pediatr Crit Care Med 2005; 6: 519-22.

15 Mariano ER, Ramamoorthy C, Chu LF, Chen M, Hammer GB. A comparison of three methods for estimating appropriate tracheal tube depth in children. Pediatr Anesth 2005; 15: 846-51.

16 Peterson J, Johnson N, Deakins K, Wilson-Costello D, Jelovsek JE, Chatburn R. Accuracy of the 7-8-9 rule for endotracheal tube placement in the neonate. J Perinatol 2006; 26: 333-6.

17 Smith GM, Reed JC, Choplin RH. Radiographic detection of esophageal malpositioning of endotracheal tubes. AJR Roentgenol 1990; 154: 23-6.

18 Salem MR. Verification of endotracheal tube position. Anesthesiol Clin North America 2001; 19: 813-39.

19 Weiss M, Knirsch W, Kretschmar O, et al. Tracheal tube-tip displacement in children during head-neck movement - a radiological assessment. Br J Anaesth 2006; 96: 486-91.

20 Yoo SY, Kim JH, Han SH, Oh AY. A comparative study of endotracheal tube positioning methods in children: safety from neck movement. Anesth Analg 2007; 105: 620-5.

21 Morell RC, Colonna DM, Mathes DD, Wilson JA. Fluoroscopy-assisted intubation of a child with an unstable subluxation of $\mathrm{C} 1 / \mathrm{C} 2$. J Neurosurg Anesthesiol 1997; 9: 25-8.

22 Reier CE, Reier AR. Radiologic-assisted endotracheal intubation. Anesth Analg 2004; 98: 1496-8.

\footnotetext{
A American Nuclear Society. http://www.ans.org/pi/resources/ dosechart/.
} 